\title{
Understanding Gender Politics in Literature: A study of The Tenant of Wildfell Hall by Anne Bronte
}

\author{
Aamir Shehzad \\ Phd Research Scholar, National University Of \\ Modern Languages Islamabad, Pakistan \\ aamirshzd@gmail.com
}

\section{Doi:10.5901/mjss.2013.v4n11p734}

\section{Abstract}

This paper attempts to analyze characterization patterns of male characters in female writing. The aim of this study is to explore the construction of female gender subjectivity while representing male characters in their novels. It has generally been considered that gender politics plays a very significant role in depicting male and female characterization in literature. Female authors engage themselves in over exaltation of female characters and display liking towards them by foregrounding the strengths of their female characters over their weaknesses; and reveal degeneration of male counterparts. Similarly male authors are inherently inclined towards male characters and reflect patriarchy in their works. It has also been analyzed that genuine representation of men by women writers and women by men writers, is not possible; there is always writer's gender subjectivity involved in the representation of characters. Gender identity and gendered representation are the focal concerns in this analysis and I have selected Anne Bronte's novel The Tenant of Wildfell Hall for my gender analysis. This research concludes that gender - apart from biological sex - plays a vital role in determining male and female characterization in literature. Female gender characteristics permeate in the portrayal of male character, language and psychology.

\section{Introduction}

Literature is generally referred as the representation of the contemporary life, as life transforms with the changing scenarios of time similarly literature is also influenced by these socio-political changes. Although it is assumed that every literary artist is somehow concerned with universalism, and depict objective and universal characters in their writings but these characters are neither objective nor timeless as they reflect history, culture as well as gender subjectivity. Every writer is as much a product of his society as his writing is the progeny of his own reaction to the life.

Gender is an important characteristic of a person's individuality. It exerts enormous impact on our lives from the time of our birth, and we act out its cultural and social aspects at crucial moments of our lives: from birth to death. Gender, apart from biological discrimination, is a social and cultural construction of masculinities and femininities. As the philosopher Simon de Beauvoir (1949) said all human beings are not born with tags of man or woman but it is society that makes them either man or woman (p. 118). We, as human beings, create gender based classification and hierarchies among ourselves. From birth, children, on the basis of gender, are given different treatments because of gender discrimination, and babies are not only dressed in different colors of clothing but are given different kinds of toys to sustain gendered division. Gender bifurcation between male and female, created in different societies and cultures, manifests itself among the reactions of people. Some of them stand against this hierarchy while others try to justify it. Similarly literary artists also bring fourth their responses in their writings.

As this study concerns gender politics in a literary text, it requires interpretation and will therefore be based on research in hermeneutical and postmodern epistemology. I will conduct a Discourse Analysis of the text under study with the backdrop of feminist literary theory in order to gain a better understanding of the hidden structures of language that are involved in gender representation. Through discourse analysis, I aim to look at the following aspects:

a. how much space is given to a character,

b. what sort of words the author employs, and

c. what is the social, cultural and historical situatedness of the characters etc,.

It will also be helpful for investigating the author's ideological dispositions evident in text.

The present study is undertaken to investigate gender politics in literature. In developing the parameters of this inquiry, the following objectives are established.

1. To understand the role and significance of gender subjectivity in representing characters in the novel. 
2. To analyze how female gender characteristics permeate in the portrayal of male character, language and psychology.

In order to determine gender identity and gender representation, we need to distinguish between sex and gender. Sexual characteristics refer to biological differences that categorize someone as male or female; while gender refers to the ideas, characteristics and practices of masculine and feminine and is constructed within a social framework. Oxford Advanced Learner's Dictionary defines gender as "sexual classification; sex, the male and female" ( $p, 171)$.

The hierarchical power associations between male and female lead to the gender discrimination, which further culminates in marginalization and exploitation of women. This distinction between genders is usually accepted as a natural phenomenon but is actually constituted by society. According to Reeves and Baden (2000), "Gender relationships among the people are determined, in a culture, by a number of different operating authorities like family relations, legal system etc. These operating authorities are the reasons that are responsible for creating certain rules or regulations to control and manipulate social institutions. Even the history reveals the fact that women were marginalized and were not given equal rights to use their power to bring about change in the social sphere" ( $p, 18)$.

Feminist Literary Theory is chiefly related to the influence of gender on writings and readings. It often takes into account social discrimination and provides a critique to the patriarchal culture that is devised to favor males. It is also concerned with the position of female writers with their male counterpart. Finally, it looks for a feminist theory or a feminist approach to the texts produced by both male and female writers. Feminists believe that gender (male or female) signifies nothing but the differences between genders are constructed and imposed by the society. Feminist theory provides a platform for the readers to look for the power structures and power practices due to gender discrimination in a certain culture are reflected and challenged by the literary authors in their texts. All major feminist critics, like Betty Friedan, Kate Millet, Ellen Moers and Elaine Showalter, adopted a female-oriented perspective focusing on literature by women and forsaking earlier exclusive emphasis on exposing sexist distortions and patriarchal stereotypes.

According to Elaine Showalter (1995) feminist literary criticism focuses on 'the woman as reader' and on 'the woman as writer'. The first type is concerned with;

\footnotetext{
"...woman being the user of the literature produced by the male writers, and is related to the ways and traditions by which the pre- suppositions of any female reader transforms our understanding of a certain text, and making us aware of the underlying importance of its textual codes... it involves the representations and stereotypical images of women in literature." $(p, 128)$
}

This kind of analysis can be called feminist critique, which attempts to investigate the ideological hypotheses of any literary phenomenon. It also takes into account the stereotypical representations of women in literature and helps to transform these pre-supposition, as we know that women are generally associated with the characteristics of motherhood, like caring, loving, taking interest in household affairs, less rational, emotional, and sensitive and similarly weak nerved, while the second type focuses on 'the woman as writer';

"... woman as the producer of textual meaning, that is how female writers differ from male writers in terms of their creativity, their linguistics underpinnings, and the course of the individual or collective literary career". (p. 128)

Feminist literary critics demonstrate in their criticism how often literary images of women are a reflection of recognizable cultural stereotypes. These recognizable cultural stereotypical images include - the woman; as morally depraved and dangerous seductress, perpetually helpless, unworldly, self-sacrificing, etc. Since the way female characters were portrayed had not much in common with the way feminist critics saw and experienced themselves. These characters were not natural but rather constructions, put together - not necessarily by the writers who presented them, but by the culture they belong to - serve not-so-hidden purpose: the continued social and cultural domination of males.

"The Tenant of Wildfell Hall" (1848), by Anne Bronte, is the story of a woman who leaves her abusive, drunken and adulterous husband and decides to bear the burden of herself and her son. Anne Bronte challenges the prevailing conventions of morality of the time. It was extensively popular and one of the most controversial novel of the time when it was published in 1848, and considered to be the first modern feminist novel. Critics of the times and later disapprove of the uneven characterization, but it was Bronte's ideas about the rights of every individual woman that caused a tumult in the mid 1800s. As in the preface Anne says;

"The underlying purpose, in writing this novel, was not simply to entertain the readers, neither was it to satisfy my own experience, nor yet to get in myself with the press and the public: I tried to convey the truth, and truth always conveys 
During the Victorian age, women were marginalized and thought of as lower than to their male counter parts. Bronte challenges this gender system by providing readers with a strong female heroine who blatantly defies laws and norms of the day by leaving her abusive and fearful husband for an autonomous existence, which overturned the prevalent socially accepted principles of the day. In that age the husband had a legal right and control over the wife and offspring, since they were considered the husband's property and it was impossible to rebel against the norms of society. Inspite of everything Bronte's female protagonist bravely walks out on her own, taking her son with her.

\section{Gendered Representation of Gilbert Markham}

Anne Bronte, challenging the prevalent norms of gender of her age, not only creates a powerful female character but also depicts feminine male character. In the novel the hero (Gilbert Markham) is presented as gender contrast; displaying a mixture of both masculine and feminine features. Gilbert Markham is a kind hearted, hard-working and passionate young farmer. The story begins with a series of letters written by Gilbert to his brother in-law; telling of his romantic experience with a mysterious woman who had came to Wildfell Hall as a new tenant. At first he was unable to win her compassions because of her coldness and aloofness, but Gilbert finally discovers her past story; and his sincere sympathy and interest in her work as a landscape painter endear him to her; and he marries his beloved.

Gilbert is a gentleman farmer, a more dynamic member of society than the idle male of the contemporary era. $\mathrm{He}$ is an important part of a well-knit domestic circle, which consists of his mother, brother and sister. From the family and social circle, Gilbert develops ideas about his future life; as opposed to the conventional norms of the time. Which dictated that after marriage, a woman had to serve her husband and do whatever was most agreeable to the men folk of the house.

Gilbert has the kind of thinking which was unlike the gentle men of the time, as when he talks about domestic responsibilities of man and woman as being equal and interdependent. According to him both husband and wife need to co-operate with each other in order to lead a happy and successful life; instead of husband exercising a commanding and powerful role. Talking to his mother, Gilbert says;

"I am not sent to this world merely to exercise the goodness of others and to take benefits from other's good feelings and good capacities - am I? - but rather it is also my obligation to put forth mine own good behavior towards them; and when I'll get marry, I'll try to make my life more pleasing in making my wife happy and comfortable,

"Well, then, we are supposed to bear one another's burdens." (p. 78, 79)

After marrying Helen, Gilbert continues embodying domestic masculinity and becomes a good, loving and caring step father to little Arthur. This domestic bent of mind and looking after his wife and stepson, displays Gilbert's feminine traits rather than masculine ones.

Gilbert is reckless and leaps to conclusion very quickly without prior consideration. When he supposes Lawrence to be in love with Helen, he immediately finds him "repugnant" and refuses to talk to him or shake hand". (p. 74)

Gilbert is obsessive, envious and changeable in temperament, but these are not negative qualities, except for the fact that he could not overcome them. Possessing qualities and characteristics that make him not fit for expectations of middle-class masculinity. Gilbert suspects that Helen and Lawrence are entangled in a love affair and in utter disappointment he states; "like a passionate child, I dashed myself on the ground and lay there in a paroxysm of anger and despair...." (p. 91)

Gilbert's character possesses female traits, while his masculine qualities underlie the dominant female qualities. Anne Bronte portrays him like a woman more than a man; raising the question whether she consciously depicts him as such or it is her gender identity which permeates into her characterization. Although the novel is an attempt to challenge the prevailing conventions about gender she is unable to rid herself of her gender biasness, as observed in the character of Gilbert Markham.

\section{Conclusion}

The foregoing discussion about gender representation in the novel justifies the fact that gender politics plays a vital role in characterization by female writers. After analyzing the salient features of Gilbert Markham, we can conclude that genuine depiction of male characters by women writers and female characters by men writers is not possible; there is 
always the writer's gender subjectivity involved in the representation. Anne Bronte in her novel "The Tenant of Wildfell Hall" portrays the character of Gilbert Markham embodying female psychological features. As a female writer she is unable to depict the male character neutrally and effectively, since her gender subjectivity is involved in the representation of male character.

\section{References}

Bronte, Anne. (1996). The Tenant of Wildfell Hall. London: Penguin classics books.

Hazel, Reeves and Sally, Baden. (2000). Gender and Development. Concepts and definition. Great Britain: Institute of Development Studies.

Showalter, Elaine. (1981). Feminist Criticism in the Wilderness. Critical Inquiry 8. University of Chicago.

Showalter, Elaine. (1995). New Feminist criticism. Essays on women, Literature and Theory. New York: Pantheon Books.

Simon de Beauvoir. (1949). The second Sex. (Constance Borde and Sheila Malovany-Chevalie Trans). France: Knopf Doubleday Publishing Group. 